\title{
Ultrasonic examination of differences in bone density of chronic obstructive pulmonary disease (COPD) rats constructed by different methods
}

\author{
Wei Wu ${ }^{1}$, Meng $\mathrm{Wu}^{2}$, Yongli Wang ${ }^{2}$, Xuesheng Jiang ${ }^{2}$, Gang $\mathrm{Li}^{3}$ \\ ${ }^{1}$ Department of Ultrasonography, ${ }^{2}$ Department of Orthopedic, Huzhou Central Hospital, Affiliated Cent Hosp Huzhou University, Huzhou, China; \\ ${ }^{3}$ Medical Oncology, Huzhou Traditional Chinese Medicine Hospital, Affiliated to Zhejiang Chinese Medical University, Huzhou, China \\ Contributions: (I) Conception and design: W Wu, M Wu, G Li; (II) Administrative support: Y Wang, X Jiang; (III) Provision of study materials or \\ patients: W Wu, M Wu, G Li; (IV) Collection and assembly of data: W Wu, M Wu, Y Wang, X Jiang; (V) Data analysis and interpretation: W Wu, \\ Y Wang, X Jiang, G Li; (VI) Manuscript writing: All authors; (VII) Final approval of manuscript: All authors. \\ Correspondence to: Gang Li. Huzhou Traditional Chinese Medicine Hospital, No. 315 Nanjie, Wuxing District, Huzhou 313000 , China. \\ Email: wuweiwuweivivian@163.com.
}

Background: Osteoporosis is one of the main complications of chronic obstructive pulmonary disease (COPD) patients. We investigated the bone density in rat model of COPD induced by different method.

Methods: We developed seven distinct groups to evaluate the differences in bone density. Based on these seven different ways, rats were categorized into distinct groups in which simple cigarette inhalation, sulfur dioxide inhalation, lipopolysaccharide intubation, protease induction, bacterial nasal injection, smoking combined with endotoxin, smoking combined bacterial infection, and smoking combined with protease were tested. The results from the male Sprague-Dawley (SD) rats were used to construct the COPD model, and then the bone density of the rats' right femurs was examined by the ultrasonic bone density testing.

Results: The compound factor-induced COPD rat model provides a better simulation of the clinical characteristics and pathophysiological processes of COPD. Smoking combined with bacterial infection method has the most apparent effect on reducing bone density, with statistical differences $(\mathrm{P}<0.05)$.

Conclusions: The COPD rat model constructed by the combination of smoking and bacterial infection method has a much lower bone density.

Keywords: Ultrasound; chronic obstructive pulmonary disease (COPD); rat; bone mineral density

Submitted Apr 09, 2020. Accepted for publication Jun 04, 2020.

doi: 10.21037/apm-20-1047

View this article at: http://dx.doi.org/10.21037/apm-20-1047

\section{Introduction}

Chronic obstructive pulmonary disease (COPD) is a chronic respiratory disease with persistent airflow limitation caused by genetic factors, airway hyperresponsiveness, other personal factors, and environmental factors such as smoking, air pollution, and respiratory tract infection (1). Currently, COPD ranks fourth among all causes of death worldwide and has become a severe public health problem (2). Osteoporosis is one of the main complications of COPD patients, and the progressive aggravation of COPD will lead to vitamin D deficiency, hypogonadism, and chronic hypoxemia. Moreover, the use of steroid drugs will also cause an occurrence of COPD and aggravate osteoporosis (3-7).

Animal models are needed to better understand the multi-faceted pathological features of COPD. Numbers of research have developed in the aspect of COPD modeling, mainly in animals such as guinea pig, rat and mouse. On top of it, an ideal model of COPD would include the crucial characteristic and co-morbidities. Age and gender 
of animals are vital elements contributed to induction of COPD model. The current method for constructing COPD rat models are divided into single factor induction and multi-factor compound induction models. The clinical characteristics and pathophysiological characteristics of COPD rats constructed by each method are different, and there are no reports about the changes in bone density in the COPD rats models, constructed by each method. Noxious inhalation including cigarette exposure and sulfur dioxide inhalation was commonly used to mimic airway collagen deposition and chronic inflammation. LPS instillation (8) would induce bacterial infection and and airway hyperresponsiveness in COPD. Other inductions including protease induction, bacterial nasal injection, smoking combined with endotoxin, smoking combined bacterial infection, and smoking combined with protease were rarely reported in early research. In this study, we investigated the bone density in rat model of COPD induced by various ways.

We present the following article in accordance with the ARRIVE reporting checklist (available at http://dx.doi. org/10.21037/apm-20-1047).

\section{Methods}

\section{Animal grouping and experiments}

All animal experiments were carried out in accordance with the NIH Guide for the Care and Use of Laboratory Animals and were approved by Zhejiang University of Traditional Chinese Medicine. Two hundred-forty SpragueDawley (SD) male rats weighing $200 \pm 8$ g (purchased from Zhejiang Experimental Animal Center, Zhejiang, Hangzhou, China, SPF grade) were raised in the Animal Experimental Center of Zhejiang University of Traditional Chinese Medicine, with feeding conditions of $25 \pm 1{ }^{\circ} \mathrm{C}$, relative humidity $40-60 \%$. Random number table methods were used to divide the rats into eight groups, with 30 animals in each group. The 30 healthy rats were further divided into the seven groups, the healthy control group, simple cigarette inhalation group, sulfur dioxide inhalation group, protease induction group, bacterial nasal infusion group, smoking combined with endotoxin group, smoking combined with bacterial infection group, and the smoking combined with protease group. Then, the cigarette inhalation group, sulfur dioxide inhalation group, smoking combined with endotoxin group, smoking combined with bacterial infection group, and smoking combined with protease group were put into the passive $49.0 \mathrm{~cm} \times 31.5 \mathrm{~cm}$ $\times 47.0 \mathrm{~cm}$ smoking box [purchased from Taizhou Medical Limited company, (location)]. The cigarettes used in this experiment were Yipinmei cigarettes produced by Jiangsu China Tobacco Company (source location). The cigarettes were $4 \mathrm{mg}$ of carbon monoxide in flue gas, $0.8 \mathrm{mg}$ of nicotine in flue gas, and $11 \mathrm{mg}$ of tar).

For the simple cigarette inhalation group, rats were smoked with a smoke concentration of $6 \%$, twice a day, half-an-hour each time with an interval of eight hours for 90 days.

* For the smoking combined with the endotoxin group, rats were smoked with a smoke concentration of $6 \%$, twice a day, half-an-hour for each time with an interval of 8 hours for 90 days. On day 30 and 60, rats were given a tracheal injection of $250 \mu \mathrm{L}$ of saline and endotoxin $(1 \mu \mathrm{g} / \mu \mathrm{L})$.

* For smoking combined with a bacterial infection group, the rats were smoked with a smoke concentration of $6 \%$, twice a day, half-an-hour each time with an interval of eight hours for ninety days. On days 15, 30, 45 and 60, rats were injected with a large amount of Klebsiella pneumonia $\left(15 \times 10^{12} \mathrm{CFU} / \mathrm{mL}\right)$ intranasally, two times per day, $0.2 \mathrm{~mL}$ each time, and the bacteria were continuously dropped for three days?

- For smoking combined protease group, rats were smoked with a smoke concentration of $6 \%$, twice a day, half-an-hour each time with an interval of eight hours for 90 days. On days 30, 32, 34, 36, and $60,62,64$, and 66 , the rats were placed in the atomization box connected to the ultrasonic atomizer. The liquid containing papain was atomized and then inputted into the atomization box, with a dosage of $2 \mathrm{~g} / \mathrm{L}, 2 \mathrm{~mL} / \mathrm{time}$.

* For sulfur dioxide inhalation group: rats are exposed to $240 \times 10^{5} \mathrm{SO}_{2}$ gas, four hours per day, five days per week, for ten weeks.

* For the Protease induction group: on days 30, 32, 34,36 , and $60,62,64$, and 66 , the rats were placed in the atomization box connected to the ultrasonic atomizer. The liquid containing papain was atomized and then inputted into the atomization box, with a dosage of $2 \mathrm{~g} / \mathrm{L}, 2 \mathrm{~mL} / \mathrm{time}$.

* For bacterial nasal injection group: On days 15, 30, 45 , and 60 , rats were injected with a large amount of Klebsiella pneumonia $\left(15 \times 10^{12} \mathrm{CFU} / \mathrm{mL}\right)$ 
intranasally, twice a day, $0.2 \mathrm{~mL}$ each time, and the bacteria were continuously dropped for 3 days.

\section{Ultrasonic examination of the bone density of the rat right femur}

The bone density of the rats' right femurs was measured using a QUUS measuring instrument Sonost 3000 (produced by OsteoSys, Shanghai, China). The results were expressed in $\mathrm{T}$ values. $\mathrm{T}$ value $\leq-2.5$ is osteoporosis, $-2.5<\mathrm{T}$ value $<-1.0$ refers to low bone mass, $\mathrm{T}$ value $\geq-1.0$ indicates normal bone mass.

\section{Detection of rat lung function}

The rats were anesthetized with 3\% pentobarbital sodium, the limbs and head of the rats were fixed in the supine position, the trachea was intubated through the oral cavity of the rat and then connected to the respiratory flow transducer. The pressure transducer was connected to the esophagus of the rat to measure the internal pressure of the esophagus, not the intrathoracic pressure. The data were recorded continuously for 35 minutes after the rat breathing is stable. The sampling frequency is $10 \mathrm{kHz}$, the time constant is 0.001 , and the biological signal acquisition and processing system (RM6240B/C type) were used to calculate the minute ventilation, compliance, and airway resistance of the lung.

\section{Detection of IL-8, TNF- $\alpha$ (tumor necrosis factor- $\alpha$ ), and PLA2 (phospholipase a2) in serum}

Five $\mathrm{mL}$ of blood from the abdominal aorta was collected and placed in a blood collection tube for 2 hours to let stand. Then, the blood samples were centrifuged at $1,200 \mathrm{r} / \mathrm{min}$ at $4{ }^{\circ} \mathrm{C}$ for 20 minutes. The supernatant was used to detect the content of IL- 8 , TNF- $\alpha$, and PLA2 in the serum according to the ELISA (enzyme-linked immunosorbent assay) method. The operation process is conducted according to the instruction of the IL- 8 , TNF- $\alpha$, and PLA2 ELISA kit (Boster, Wuhan, China).

\section{Detection of lung tissue mean alveolar diameter (LM) and mean alveolar number (MAN)}

After the rats were sacrificed, conventional pathological sections were made. Then, three fields of view (magnification 200x) were randomly selected for each section, and the number of alveoli in each field of view was calculated. The diameter of each alveolar was measured. The average value was calculated as LM, and the number of alveoli was divided by the area of the field of view is MAN.

\section{Statistical analysis}

All experiments were performed three times or more independently, and all experimental data were presented as the mean \pm standard deviation (SD). The statistical analyses between the two groups were conducted by using Student's $t$ tests and SPSS 22.0 software (SPSS Inc.). And the $\mathrm{P}<0.05$ were considered statistically significant. Differences were considered significant at $\mathrm{P}<0.05$.

\section{Results}

\section{Rat clinical symptoms after the COPD modeling}

After modeling, rats developed wheezing, dyspnea, coughing, and shortness of breath. The body showed weight loss, tired look, dull fur, yellowish urine, and dry stool. Among them, the rats induced by multiple factors showed more severe symptoms, and the rats constructed by smoking combined with bacterial infection showed the most severe symptoms. The healthy control rats showed no visible abnormal signs.

\section{Results of MAN and LM in lung tissue of rats}

LM and MAN were used to evaluate the severity of emphysema in rats, the LM value reflects the average diameter of the alveoli, and the MAN value reflects the density of the alveoli. After COPD modeling, compared to the normal rats, the COPD model had a larger LM and smaller MAN, with statistical significance $(\mathrm{P}<0.05)$. Among them, the rats model constructed by the smoking method combined with the bacterial infection method has a larger LM and smaller MAN than those constructed by other methods, with statistical significance $(\mathrm{P}<0.05)$, and also has the most apparent emphysema, see Table 1 .

\section{Changes in the rats' lung function}

The lung function of eight groups of rats was detected by the biological signal acquisition system (RM6240B/C). The results showed that both airway resistance and lung elastic resistance increased, but lung compliance decreased 
Table 1 Average alveolar number and alveolar diameter

\begin{tabular}{lcc}
\hline Groups & Mean alveolar diameter $(\mu \mathrm{m})$ & Mean alveolar number $\left(10^{6} / \mathrm{m}^{2}\right)$ \\
\hline Healthy control group & $26.3 \pm 1.6$ & $22.1 \pm 1.5$ \\
Simple cigarette inhalation group & $31.5 \pm 3.5^{\mathrm{a}}$ & $18.1 \pm 1.2^{\mathrm{a}}$ \\
Sulfur dioxide inhalation group & $32.7 \pm 4.1^{\mathrm{a}}$ & $17.9 \pm 1.4^{\mathrm{a}}$ \\
Bacterial nasal injection group & $33.4 \pm 3.1^{\mathrm{a}}$ & $17.5 \pm 1.3^{\mathrm{a}}$ \\
Protease induction group & $35.1 \pm 4.2^{\mathrm{a}}$ & $17.1 \pm 1.5^{\mathrm{a}}$ \\
Smoking combined proteome & $38.2 \pm 3.1^{\mathrm{a}}$ & $16.3 \pm 1.2^{\mathrm{a}}$ \\
Smoking combined endotoxin group & $39.1 \pm 4.3^{\mathrm{a}}$ & $16.1 \pm 1.5^{\mathrm{a}}$ \\
Smoking combined bacterial infection group & $43.5 \pm 4.2^{\mathrm{a}, \mathrm{b}}$ & $12.3 \pm 1.7^{\mathrm{a}, \mathrm{b}}$ \\
P value & $<0.05$ & $<0.05$ \\
\hline
\end{tabular}

a , $\mathrm{P}<0.05$, compared with healthy control rats; ${ }^{\mathrm{b}}, \mathrm{P}<0.05$, compared with the cigarette inhalation group, sulfur dioxide inhalation group, bacterial nasal injection group, protease induction group, smoking combined protease group, smoking combined endotoxin group, respectively.

Table 2 Changes in lung function

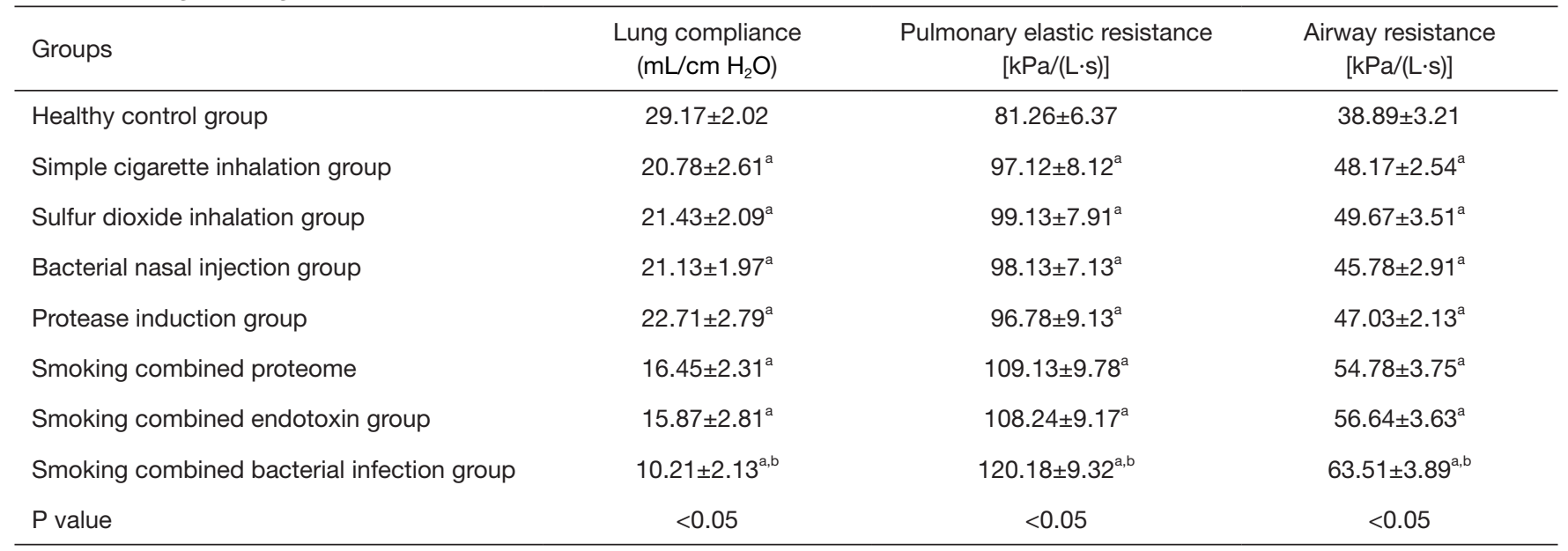

${ }^{\mathrm{a}}, \mathrm{P}<0.05$, compared with healthy control rats; ${ }^{\mathrm{b}}, \mathrm{P}<0.05$, compared with the cigarette inhalation group, sulfur dioxide inhalation group, bacterial nasal injection group, protease induction group, smoking combined protease group, smoking combined endotoxin group, respectively.

in the COPD rats, with statistical significance $(\mathrm{P}<0.05)$. Among those groups, rats in the smoking combined bacterial infection group had more significant changes than those induced by other induction methods, with statistical significance $(\mathrm{P}<0.05)$, see Table 2 .

\section{Changes in inflammatory factors in rat serum}

The levels of PLA2, IL-8, and TNF- $\alpha$ in the serum of rats were detected by enzyme-linked immunosorbent assay. The levels of PLA2, IL-8, and TNF- $\alpha$ in the COPD rat model were higher compared with those in the healthy control group, with statistically significant $(\mathrm{P}<0.05)$. Among those groups, the contents of PLA2, IL- 8 , and TNF- $\alpha$ in the smoking combined with bacterial infection group were higher than those of other groups, with statistical significance $(\mathrm{P}<0.05)$, see Table 3.

\section{Bone mineral density differences between different models of COPD rats}

The bone density of rats with a well-established COPD 
Table 3 Contents of IL- 8 , TNF- $\alpha$, and PLA2 in the rat serum

\begin{tabular}{lccc}
\hline Groups & PLA2 (U/L) & IL-8 $(\mathrm{pg} / \mathrm{mL})$ & $\mathrm{TNF}-\alpha(\mathrm{pg} / \mathrm{mL})$ \\
\hline Healthy control group & $118.12 \pm 3.15$ & $236.32 \pm 15.73$ & $45.91 \pm 2.19$ \\
Simple cigarette inhalation group & $146.23 \pm 4.32^{\mathrm{a}}$ & $341.14 \pm 20.31^{\mathrm{a}}$ & $71.63 \pm 2.13^{\mathrm{a}}$ \\
Sulfur dioxide inhalation group & $143.21 \pm 3.98^{\mathrm{a}}$ & $351.32 \pm 18.74^{\mathrm{a}}$ & $81.02 \pm 3.12^{\mathrm{a}}$ \\
Bacterial nasal injection group & $139.97 \pm 5.18^{\mathrm{a}}$ & $362.13 \pm 17.95^{\mathrm{a}}$ & $78.15 \pm 3.17^{\mathrm{a}}$ \\
Protease induction group & $138.38 \pm 4.71^{\mathrm{a}}$ & $350.98 \pm 24.15^{\mathrm{a}}$ & $79.13 \pm 2.14^{\mathrm{a}}$ \\
Smoking combined proteome & $156.14 \pm 4.78^{\mathrm{a}}$ & $400.13 \pm 31.24^{\mathrm{a}}$ & $98.71 \pm 3.08^{\mathrm{a}}$ \\
Smoking combined endotoxin group & $152.15 \pm 3.79^{\mathrm{a}}$ & $405.25 \pm 31.05^{\mathrm{a}}$ & $99.17 \pm 3.97^{\mathrm{a}}$ \\
Smoking combined bacterial infection group & $168.39 \pm 4.94^{\mathrm{a}, \mathrm{b}}$ & $460.97 \pm 32.17^{\mathrm{a}, \mathrm{b}}$ & $120.34 \pm 4.51^{\mathrm{a}, \mathrm{b}}$ \\
P value & $<0.05$ & & \\
\hline
\end{tabular}

${ }^{\mathrm{a}}, \mathrm{P}<0.05$, compared with healthy control rats; ${ }^{\mathrm{b}}, \mathrm{P}<0.05$, compared with the cigarette inhalation group, sulfur dioxide inhalation group, bacterial nasal injection group, protease induction group, smoking combined protease group, smoking combined endotoxin group, respectively.

Table 4 Bone mineral density differences between different models of COPD rats

\begin{tabular}{|c|c|c|c|c|}
\hline Groups & Number of cases & $T$ value $\geq-1.0$ & $-2.5<\mathrm{T}$ value $<-1.0$ & T value $\leq-2.5$ \\
\hline Simple cigarette inhalation group & 30 & $20(66.7 \%)^{a}$ & $7(23.3 \%)^{a}$ & $3(10 \%)^{a}$ \\
\hline Sulfur dioxide inhalation group & 30 & $21(70.0 \%)^{a}$ & $7(23.3 \%)^{\mathrm{a}}$ & $2(6.7 \%)^{a}$ \\
\hline Bacterial nasal injection group & 30 & $21(70.0 \%)^{a}$ & $6(20.0 \%)^{a}$ & $3(10.0 \%)^{a}$ \\
\hline Smoking combined proteome & 30 & $17(56.7 \%)^{\mathrm{a}}$ & $7(23.3 \%)^{a}$ & $6(20.0 \%)^{a}$ \\
\hline Smoking Combined Endotoxin Group & 30 & $17(56.7)^{\mathrm{a}}$ & $6(20.0 \%)^{a}$ & $7(23.3 \%)^{a}$ \\
\hline Smoking combined bacterial infection group & 30 & $11(36.7 \%)^{a, b}$ & $10(33.3 \%)^{a, b}$ & $9(30.0 \%)^{a, b}$ \\
\hline$P$ value & $<0.05$ & & & \\
\hline
\end{tabular}

${ }^{\mathrm{a}}, \mathrm{P}<0.05$, compared with healthy control rats; ${ }^{\mathrm{b}}, \mathrm{P}<0.05$, compared with the cigarette inhalation group, sulfur dioxide inhalation group, bacterial nasal injection group, protease induction group, smoking combined protease group, smoking combined endotoxin group, respectively. COPD, chronic obstructive pulmonary disease.

model decreased more than that of healthy control rats, and it was statistically significant $(\mathrm{P}<0.05)$. The bone density of rats constructed by smoking combined with the bacterial infection method was reduced more dramatically than those of the COPD rats model constructed by other methods, with statistical significance $(\mathrm{P}<0.05)$, see Table 4.

\section{Discussion}

COPD is a disease with high morbidity and high mortality.
At present, most of the research on COPD animal experiments is based on the COPD rat model. The current mainstream COPD rat model construction methods are a smoking method and smoking with infection, endotoxin, or other factors. Smoke exposure is a common risk factor for COPD. At present, some studies believe that smoke exposure induces oxidation of lipids and cell membrane components through oxygen-free radicals, which activates the oxidative stress pathway of cells, resulting in damage to DNA and the airway (9). Infection is a significant risk factor for chronic inflammation, and related studies have shown that bacterial 
infections based on smoke exposure can worsen lung inflammation. Current research has also shown that among the methods used to construct the COPD rat model, smoking combined with endotoxin, bacterial infection, or other factors is more effective than single factor induction (10). COPD is a disease with progressive airflow limitation accompanied by the increase of chronic inflammation of the airway caused by harmful particles and gas. It is often complicated by cardiovascular diseases, osteoporosis, metabolic syndrome, depression, and other diseases (11-19). Due to the lack of an ideal model of COPD with osteoporosis, progress in the exploration of its mechanism is not enough. We have conducted ultrasonic bone density testing of the rats set up by the current mainstream methods of rat COPD model construction. The methods of COPD construction in rats can induce the clinical symptoms and pathophysiological process of COPD to a certain extent, but the degree is different. Among these different methods, the rats with multi-factor combined induction of COPD are more evident in clinical characteristics and pathophysiological processes than those with single-factor induced COPD, with a statistical difference $(\mathrm{P}<0.05)$. Moreover, among the methods of multi-factor combined induction of COPD, smoking combined with bacterial infection method has the most remarkable effect. Ultrasonic bone mineral density testing of experimental rats revealed that normal healthy mice had typical bone mineral density levels, and the bone density of rats with well-established COPD decreased significantly, with statistical differences. The mineral density of multi-factor induced COPD rats decreased significantly compared with that of single factor-induced COPD rats and with statistically significance $(\mathrm{P}<0.05)$. Furthermore, among all the groups, the bone density of COPD rats induced by smoking combined with bacterial infection group was reduced most dramatically compared to those of other groups. It is considerable that smoke exposure increased susceptibility to bacterial infection while bacterial infection may cause exacerbations of COPD. Notably, frequent exacerbators had a higher risk of osteoporosis. This study shows that the rat model of COPD induced by smoking combined with bacterial infection is more evident in many clinical features and bone density reduction, which is not only an ideal method for constructing a COPD rat model, but also for screening out a rat model of COPD with osteoporosis.

\section{Acknowledgments}

Funding: This work supported by Zhejiang Provincial
Public Welfare Technology Applied Research Laboratory Animal Project (No. 2017C37119) and Huzhou Public Welfare General Project (No.2018GYB42).

\section{Footnote}

Reporting Checklist: The authors have completed the ARRIVE reporting checklist. Available at http://dx.doi. org/10.21037/apm-20-1047

Data Sharing Statement: Available at http://dx.doi. org/10.21037/apm-20-1047

Conflicts of Interest: All authors have completed the ICMJE uniform disclosure form (available at http://dx.doi. org/10.21037/apm-20-1047). The authors have no conflicts of interest to declare.

Ethical Statement: The authors are accountable for all aspects of the work in ensuring that questions related to the accuracy or integrity of any part of the work are appropriately investigated and resolved. All animal experiments were carried out in accordance with the NIH Guide for the Care and Use of Laboratory Animals. The Committee for Animal Experiments of Zhejiang University of Traditional Chinese Medicine approved all of the experiments involving animals (No. 2019056).

Open Access Statement: This is an Open Access article distributed in accordance with the Creative Commons Attribution-NonCommercial-NoDerivs 4.0 International License (CC BY-NC-ND 4.0), which permits the noncommercial replication and distribution of the article with the strict proviso that no changes or edits are made and the original work is properly cited (including links to both the formal publication through the relevant DOI and the license). See: https://creativecommons.org/licenses/by-nc-nd/4.0/.

\section{References}

1. Smith MC, Wrobel JP. Epidemiology and clinical impact of major comorbidities in patients with COPD. Int J Chron Obstruct Pulmon Dis 2014;9:871-88.

2. Ko FW, Chan KP, Hui DS. Comprehensive care for chronic obstructive pulmonary disease. J Thorac Dis 2019;11:S2181-91.

3. Moberg M, Ringbaek T, Roberts NB, et al. Association between vitamin $\mathrm{D}$ status and COPD phenotypes. Lung 
2014;192:493-7.

4. Zendedel A, Gholami M, Anbari K, et al. Effects of Vitamin D Intake on FEV1 and COPD Exacerbation: A Randomized Clinical Trial Study. Glob J Health Sci 2015;7:243-8.

5. Yang B, Choi H, Lim JH, et al. The disease burden of bronchiectasis in comparison with chronic obstructive pulmonary disease: a national database study in Korea. Ann Transl Med 2019;7:770.

6. Andrianopoulos V, Franssen FM, Peeters JP, et al. Exercise-induced oxygen desaturation in COPD patients without resting hypoxemia. Respir Physiol Neurobiol 2014;190:40-6.

7. Similowski T, Suissa S. Systemic steroids in severe forms of COPD exacerbations: a question of balance? Eur Respir J 2014;43:668-70.

8. Ghorani V, Boskabady MH, Khazdair MR, et al. Experimental animal models for COPD: a methodological review. Tob Induc Dis 2017;15:25.

9. Domej W, Oettl K, Renner W. Oxidative stress and free radicals in COPD--implications and relevance for treatment. Int J Chron Obstruct Pulmon Dis 2014;9:1207-24.

10. Fang S, Gu W, Tan Y, et al. Establishment of COPD rat model using the airway infused with lipopolysaccharide (LPS) and fumed by cigarette. Acta Universitatis Medicinalis Nanjing 2013;(9):1226-30.

11. Lyzogub VH, Savchenko OV, Zaval's'ka TV, et al.

Cite this article as: $\mathrm{Wu} \mathrm{W}, \mathrm{Wu} \mathrm{M}$, Wang $\mathrm{Y}$, Jiang $\mathrm{X}, \mathrm{Li} \mathrm{G}$. Ultrasonic examination of differences in bone density of chronic obstructive pulmonary disease (COPD) rats constructed by different methods. Ann Palliat Med 2020;9(4):1872-1878. doi: 10.21037/apm-20-1047
The Effects of Hypoxia on Initiation and Progression of Cardiovascular Disease in Patients With Chronic Obstructive Pulmonary Disease. Lik Sprava 2012;(5):27-34.

12. Bhatt SP, Dransfield MT. Chronic obstructive pulmonary disease and cardiovascular disease. Transl Res 2013;162:237-51.

13. Visca D, Aiello M, Chetta A. Cardiovascular function in pulmonary emphysema. Biomed Res Int 2013;2013:184678.

14. Inoue D, Watanabe R, Okazaki R. COPD and osteoporosis: links, risks, and treatment challenges. Int J Chron Obstruct Pulmon Dis 2016;11:637-48.

15. Breyer MK, Spruit MA, Hanson CK, et al. Prevalence of metabolic syndrome in COPD patients and its consequences. PLoS One 2014;9:e98013.

16. Vancampfort D, Probst M, Stubbs B, Soundy A, et al. Metabolic syndrome and lung function in schizophrenia: a pilot study. Psychiatry Res 2014;220:58-62.

17. Park SK, Larson JL. Metabolic syndrome and associated factors in people with chronic obstructive pulmonary disease. West J Nurs Res 2014;36:620-42.

18. Yohannes AM, Alexopoulos GS. Depression and anxiety in patients with COPD. Eur Respir Rev 2014;23:345-9.

19. Panagioti M, Scott C, Blakemore A, et al. Overview of the prevalence, impact, and management of depression and anxiety in chronic obstructive pulmonary disease. Int J Chron Obstruct Pulmon Dis 2014;9:1289-306. 